\title{
Significados do estágio em Unidades Básicas de Saúde para estudantes de graduação
}

\author{
Lucimar Aparecida Britto Codato*; Mara Lúcia Garanhani**; Alberto Durán González***; Daniela \\ Lemos Carcereri****; Brigida Gimenez Carvalho*****; Maria Celeste Morita*******
}

* Doutora em Saúde Coletiva, Professora Adjunta, Departamento de Medicina Oral e Odontologia Infantil, Universidade Estadual de Londrina

** Doutora em Enfermagem, Professora Associada, Departamento de Enfermagem, Universidade Estadual de Londrina

*** Doutor em Saúde Coletiva, Professor Adjunto, Departamento de Saúde Coletiva, Universidade Estadual de Londrina

**** Pós-doutora pela Universidade de Barcelona, Professora Associada, Departamento de Odontologia, Universidade Federal de Santa Catarina

***** Doutora em Gerenciamento em Enfermagem, Professora Adjunta, Departamento de Saúde Coletiva, Universidade Estadual de Londrina

******* Pós-doutora pela Universidade de São Paulo, Professora Associada, Departamento de Medicina Oral e Odontologia Infantil, Universidade Estadual de Londrina.

Recebido em 22/04/2018. Aprovado em 26/12/2018.

\begin{abstract}
RESUMO
Trata-se de pesquisa qualitativa, com abordagem fenomenológica hermenêutica, apoiada nos ensinamentos de Martin Heidegger que buscou compreender os significados do estágio em Unidade Básica de Saúde (UBS), entendido como uma possibilidade de habitar e 'ser-com-outro' no mundo do trabalho, para dez estudantes do último ano da graduação. Para os pesquisados, coabitar o mundo da UBS é percebido como cumprimento de uma orientação educacional obrigatória, que pode qualificar a formação e também uma possibilidade de as pessoas envolvidas ensinarem e aprenderem. Porém, o estudo desvelou a necessidade de fortalecimento da comunicação entre docentes e estudantes para que as intencionalidades e as potencialidades da integração ensino-serviço de saúde estejam mais claras para os estudantes. Os estudantes parecem ter sido lançados na UBS sem muito conhecimento e apropriação em relação ao porquê de eles vivenciarem este espaço existencial.
\end{abstract} Descritores: Estágios. Pesquisa Qualitativa. Educação Superior. Atenção Primária à Saúde. Serviços de Integração Docente-Assistencial. 


\section{INTRODUÇÃO}

Historicamente a integração ensino-serviço de saúde, com foco na Atenção Básica, tem sido reconhecida como necessária e estratégica para a formação profissional em saúde ${ }^{1-4}$.

Há responsabilidades compartilhadas entre os serviços públicos de saúde e as instituições de ensino superior (IES) porque ambos são responsáveis pela formação e pela produção do cuidado em saúde. Nesse mosaico multifacetado há várias engrenagens que necessitam estar e atuar de forma sincrônica. Por isso, espera-se que sejam movimentos interligados e integrados, com estabelecimento de relações de parceria e trabalho conjunto.

Assim, as instituições formadoras em saúde necessitam diversificar os cenários de ensinoaprendizagem para além da sala de aula, visando à ampliação da compreensão da complexidade do processo saúde-doença e a do cuidado de pessoas, a partir de variadas realidades socioeconômicas, culturais e ambientais ${ }^{5-8}$. Outro aspecto a ser considerado é a realidade brasileira, na qual a formação profissional é estratégica e fundamental para o Sistema Único de Saúde (SUS) $)^{9-11}$. O alcance de avanços na efetividade do SUS, por meio de trabalho humanizado, interprofissional, interdisciplinar, em redes de atenção e pautado em princípios éticos também diz respeito à formação experienciada pelos estudantes durante a graduação, pois estes serão os futuros profissionais que atuarão no cuidado da população.

Neste estudo, o estágio realizado em Unidade Básicas de Saúde (UBS) é entendido como uma possibilidade de habitar o mundo do trabalho. Para Martin Heidegger ${ }^{12}$, o mundo no qual o ser humano existe não é uma caixa que se caracteriza pelo uso da razão e nem um espaço que contém tudo que existe. Mundo, para Heidegger, é anterior ao mundo espacial, topográfico e interior. É fundamentado no 'ser-em', que tem o sentido de habitar e morar. Mundo circundante é o mais próximo do 'ser-aí' dentro de sua circunvisão. 'Ser$a i^{\prime}$, tradução espanhola do que Heidegger denomina 'Dasein', é a pessoa humana que possui a capacidade de questionar, indagar o sentido do seu ser, empreender uma busca sobre si e sempre compreender a si mesma a partir de sua existência.

$\mathrm{O}$ 'ser-ai' possui a tendência de compreender sua própria existência a partir dos 'entes' com quem se relaciona e se comporta, de modo essencial, a partir do mundo. Heidegger ${ }^{12}$, designa 'ente' muitas coisas, em sentidos diversos. Inclui tudo que falamos, processos naturais, acontecimentos históricos, relações numéricas e espaciais. O próprio homem é um 'ente', no qual a questão do ser foi esquecida, porque ao invés de questioná-lo, concebeu-se o homem como um ser simplesmente dado, em conjunto com as demais coisas criadas. Logo, habitar o mundo da UBS é uma relação de coexistência entre 'ser-aí' docentes, estudantes, profissionais e usuários.

Este artigo, derivado da compreensão de uma das inquietações que moveram a realização de um estudo mais amplo ${ }^{13}$, tem como objetivo analisar os significados de habitar o mundo da UBS para os 'ser-aí' estudantes dos últimos anos de graduação em saúde que realizam estágio neste espaço existencial.

\section{METODOLOGIA}

Trata-se de pesquisa de natureza qualitativa com abordagem fenomenológica hermenêutica cuja análise dos dados foi apoiada, não exclusivamente, no referencial de Martin Heidegger ${ }^{12}$.

A pesquisa fenomenológica busca os significados, que são expressões claras sobre as percepções que a pessoa tem daquilo que está sendo investigado, remete à totalidade das experiências vividas por um indivíduo. Nela, o pesquisador não está preocupado com os fatos e sim com o que os eventos significam para os pesquisados, mais precisamente sob o ângulo do 
sentido que esses fenômenos têm para aqueles que os vivenciam $^{14,15}$.

A hermenêutica é uma importante corrente do pensamento filosófico do século XX. Refere-se à arte da interpretação de forma ampliada. Inclui a compreensão de processos de experiência de vida em que a linguagem escrita, falada ou simbólica demonstra aspectos da realidade humana. Auxilia a revelação, a descoberta e o desvelamento de significados em textos ou linguagens e também das relações que são estabelecidas. Portanto, possibilita a compreensão do homem, de seu mundo e do próprio existir humano ${ }^{16-18}$.

O filosofar heideggeriano tem como característica a constante interrogação. Busca revelar o próprio objeto de interrogação por meio da compreensão. $\mathrm{O}$ seu trabalho foca o sentido do ser, seus modos e maneiras de expressão por meio da compreensão da experiência vivida ${ }^{14,15,18}$.

Nesta etapa da pesquisa, participaram dois estudantes do último ano de graduação de cada um dos cinco cursos da área da saúde de uma universidade pública do sul do Brasil (Enfermagem, Fisioterapia, Odontologia, Medicina e Farmácia), que realizavam estágios em quatro UBS que foram indicadas na fase exploratória da pesquisa pelos gestores do serviço de saúde e pelos coordenadores de cursos, por serem as que recebiam a maior quantidade $\mathrm{e}$ diversidade de estudantes da instituição de ensino proponente. Assim, nesta amostra intencional, foram realizadas dez entrevistas, que se mostraram suficientes para a compreensão e interpretação deste aspecto do fenômeno integração ensinoserviço de saúde.

As entrevistas foram realizadas pela pesquisadora principal e transcritas por três pessoas com experiência nesta atividade, de forma integral e literal, com o objetivo de manter a maior fidelidade possível das expressões, termos e conteúdos paraverbais (entoações, ênfases, pausas) que foram manifestados pelos participantes da pesquisa. Após essa etapa, a referida pesquisadora ouviu todas as gravações e conferiu as transcrições das entrevistas. Segundo Merighi ${ }^{19}$, esse momento é uma oportunidade para o pesquisador familiarizar-se com as descrições e para começar a identificação de aspectos relevantes relacionados à pesquisa.

Para manter o anonimato, as entrevistas realizadas receberam codificação alfa-numérica. Assim E3 significa o terceiro estudante entrevistado. As questões norteadoras para estas entrevistas foram: 1) $\mathrm{O}$ que significa para você estar na UBS? 2) Como você percebe o seu estágio na UBS?

Cabe ressaltar que estas questões se adaptaram à dinâmica e singularidade de cada entrevista. Houve aspectos que surgiram e/ou foram aprofundados a partir de questionamentos derivados das respostas dos entrevistados.

A técnica de análise dos dados utilizou os procedimentos preconizados por Josgrilberg ${ }^{20}$ para a realização da busca do sentido da integração ensino-serviço, entendido como fenômeno a ser desvelado. Inicialmente cada transcrição, individualmente, foi lida e relida várias vezes. Num segundo momento, foram identificadas as unidades de sentido relacionadas à integração ensino-serviço de saúde de cada entrevista. Após, foram identificadas as unidades de sentido para os estudantes Em seguida, as unidades de sentido de todos os grupos foram relacionadas entre si, buscando-se os pontos de ligação para revelar os significados da integração ensino-serviço de saúde. Essas duas últimas etapas foram desenvolvidas por meio da elaboração de vários mapas conceituais. $\mathrm{O}$ salto para "dentro" do círculo hermenêutico aconteceu por meio de reflexão, pela busca da singularidade e da pluralidade que oportunizou a interpretação e a compreensão do fenômeno. Nesta etapa também foi utilizado o diário de campo que, em alguns momentos, contribuiu para ampliar a compreensão do fenômeno. 
A pesquisa foi aprovada pelo Comitê de Ética em Pesquisa da Universidade Estadual de Londrina (CAAE 21677913.4.0000-5231) e seguiu os pressupostos da resolução 466/12 do Conselho Nacional de Saúde ${ }^{21}$.

\section{RESULTADOS E DISCUSSÃO}

Para os estudantes entrevistados, habitar o mundo da UBS significa cumprimento de atividade curricular obrigatória em um espaço extramuros.

Esse é um estágio obrigatório que a gente tem que fazer. E2

Está no currículo, não temos escolha, temos que fazer este estágio na UBS. E4

$\mathrm{O}$ estudo desvelou que os estudantes não tinham muita clareza sobre a amplitude da intencionalidade que move a sua inserção no mundo da UBS. Anotações no caderno de campo auxiliaram a compreensão de que os estudantes parecem entender que se trata de uma iniciativa individual e isolada de uma IES, desvinculada de um macrocontexto e de orientações nacionais e internacionais, que vai muito além do cumprimento de mais um estágio curricular.

No entanto, a postura impessoal de cumprimento desta tarefa chamou a atenção. De maneira aplicada aos ensinamentos de Heidegger, este resultado pode ser compreendido como um modo impróprio de ser porque o estudante habita este espaço para cumprir uma tarefa e "ganhar uma nota", não se coloca, de fato, dentro uma ocupação.

Os estudantes parecem ter sido lançados em UBS sem muito conhecimento e apropriação em relação à intencionalidade de eles vivenciarem este espaço existencial. Um aspecto a ser considerado é a necessidade de fortalecimento da comunicação entre docentes e coordenadores de cursos com os estudantes, para ampliação da compreensão sobre a relevância da integração ensino-serviço de saúde. $\mathrm{O}$ entendimento do projeto pedagógico pelos sujeitos envolvidos, aliado a momentos de interlocuções entre pessoas da universidade, serviços, lideranças comunitárias, conselhos de saúde pode favorecer $o$ entendimento do significado e das potencialidades da integração ensino-serviço de saúde. 'Ser-com-outro' no espaço existencial da UBS é uma possibilidade sempre aberta para a qualificação da formação em saúde e para o cuidado da população.

Quando o estudante compreende e se abre para as potencialidades de 'ser-com-outro' no espaço existencial da UBS, o estágio é percebido como meio para a qualificação de seu processo formativo.

Não é meramente só pela obrigação de estar aqui, mas estar aqui e levar daqui alguma coisa para o meu aprendizado mesmo. E6

Eu acho que para formação nossa é importante a gente estar aqui, conviver, passar mais tempo e participar dessas atividades da UBS. E5

A participação do estudante neste mundo do trabalho passa a significar possibilidade de aprendizado, para além do cumprimento de uma atividade obrigatória, vai em direção a um modo de ser mais próprio. $\mathrm{O}$ envolvimento do estudante na cotidianidade da UBS pode levar à ampliação do entendimento em relação ao significado desta aproximação entre os dois mundos.

Um desafio comum a todas as profissões de saúde diz respeito à formação com desenvolvimento de valores humanizadores com alta qualidade e resolubilidade. A aproximação do processo formativo à prática dos serviços pode favorecer o desenvolvimento desta formação, porque possibilita que o estudante pense, aja e reaja às situações apresentadas com determinadas formas e padrões de atitudes ${ }^{22}$. Logo, a formação em saúde precisa fortalecer o modelo de atenção à saúde "usuário centrado", comprometido essencialmente com as necessidades das pessoas, em contrapartida ao modelo ainda predominante, "procedimento centrado"23. Almeja-se formação 
de um futuro profissional propositivo, criativo, questionador e que busque soluções para o enfrentamento das necessidades apresentadas e/ou identificadas ${ }^{6,9}$.

Assim, para os estudantes pesquisados, 'sercom-outro' na UBS também significa possibilidade de agregar valor à formação.

A gente ter esse contato mais próximo com a população acho que é importante para gente vê a necessidade também, para gente não ficar tão focado naquela área hospitalar, naquele par te de enfermaria. A gente vê mesmo a necessidade até, a parte psicológica que a gente vê. E4

Estar aqui é oportunidade para ter essa visão ampliada e não focada só na doença, como muitas vezes no hospital acontece. Aqui (UBS) é diferente, você conhece toda a família do paciente. E10

Neste resultado, a agregação de valor para a formação desvela-se ligada à possibilidade aberta de 'ser-com' a população. Diz respeito à possibilidade de ampliação do olhar e também de realização de trabalhos importantes para a população. 'Ser-com' constitui o 'ser-no-mundo'. $\mathrm{O}$ 'ser-ai' existe com e junto aos entes que vêm ao encontro dentro do mundo ${ }^{12}$. Nesta situação, percebe-se que 'ser-com' o usuário pode favorecer a compreensão sobre as necessidades de saúde da população, sobre as demandas dos serviços de saúde e também em relação à complexidade do processo saúde doença, porque abre uma possibilidade de 'ser-com' o usuário.

A convivência na cotidianidade dos serviços de saúde significa possibilidade de vivenciar o cuidado possível e/ou oferecido nas UBS, em contextos regionais e epidemiológicos específicos. Oportuniza ensino-aprendizagem mais próximo das demandas do SUS. Este contato com a realidade, por meio do 'ser-com-outro', é uma possibilidade aberta para ampliação da compreensão e para a ressignificação de valores e atitudes.

Tais valores e atitudes podem ser despertados e/ou reavivados em todas as pessoas que coexistem na UBS. O ensinar e o aprender são possibilidades sempre abertas no 'ser-com-outro's. Quando o estudante compartilha o espaço com os profissionais, estes se sentem estimulados a estudar. Além disso, a presença do estudante desperta para a complexidade do cuidado que exige não somente elementos técnico-científicos, mas também atitudes de mobilização diante de realidades adversas. Somado ao fato que as ações, discussões, reflexões e trocas de saberes contribuem para mudanças das práticas ${ }^{9}$.

A educação em saúde depende da interação com o outro, a partir de indagações, críticas e reflexões conectadas com a prática vivenciada e compartilhada pelas pessoas, as quais ora ensinam, oram aprendem. $\mathrm{O}$ caminho é permeado a partir necessidades e possibilidades identificadas pelos envolvidos. Não é algo linear e previsível ${ }^{23}$.

Assim, quando os estudantes compreendem as potencialidades da Unidade Básica de Saúde, 'ser-com-outro' na UBS significa oportunidade de ensinar e aprender.

Tanto eu ir atrás (dos profissionais), como eles virem atrás também de mim. Por exemplo, aqui tem uma enfermeira que sempre está puxando a gente. Ela chama bastante e também, às vezes, muitas das vezes, vou atrás e também quero saber, quero aprender. Vou atrás das ACS e digo que quero fazer uma visita com vocês, quero conhecer o território.. Eles procuram muito a gente para tirar dúvidas. E10

A gente tem que aprender, meio que por nós mesmos, aqui dentro (UBS). A gente tem que correr atrás, saber como as coisas funcionam. Eu acho importante nesse sentido da gente estar aprendendo por conta assim, sabendo se virar. E1 
Habitar o mundo da UBS revela-se como possibilidade aberta para a busca ativa do conhecimento, do autoaprendizado, do desenvolvimento da comunicação, da crítica e da reflexão. A formação profissional não se limita ao diagnóstico, tratamento, prognóstico e prevenção de doenças em ambientes restritos. Além da indispensável competência técnica, espera-se que o processo formativo desperte no estudante valores relacionados ao conceito ampliado de saúde, atenção à saúde, integralidade da atenção, ética, indissociabilidade entre teoria e prática, trabalho interprofissional e interdisciplinar, humanização da atenção e reconhecimento do caráter social do processo saúde doença.

Neste resultado, percebeu-se também que algumas das orientações das DCN estão sendo experenciadas pelos estudantes nas UBS como a possibilidade de aprender e ensinar, a busca ativa do conhecimento, o autoaprendizado, a crítica, o desenvolvimento da comunicação, trabalho interprofissional e interdisciplinar, integralidade da atenção e cidadania. Emergiu a reflexão que as intencionalidades que movem gestores e docentes a buscarem integrar ensino-serviço de saúde parecem encontrar sintonia com o que é vivenciado pelos estudantes quando habitam a UBS. Consideramos que o entendimento da experiência concreta do vivido pelos estudantes é o ponto central para compreender se a intencionalidade que norteia o processo formativo está sendo ou não alcançada. É algo imprevisível, sempre em construção e inacabado, porque envolve relações entre pessoas, as quais sempre têm em aberto a possibilidade de fazer escolhas.

\section{CONSIDERAÇÕES FINAIS}

O significado de habitar o mundo da UBS desvelou-se dependente das compreensões e envolvimentos de cada estudante. Depende também das relações que são estabelecidas neste espaço existencial.
As pessoas estabelecem uma relação de conformidade com o mundo. A pessoa, ao entrar no mundo em diferentes espaços, adquire conformidade com o mundo na identidade. Ao tomar forma do mundo em que habita, ela absorve parte desse mundo que vai se integrando, deixando de ser algo estranho. Neste contexto, a pessoa dá mais liberdade para ser. Não necessariamente pela razão, mas em torno da possibilidade de apropriarse das coisas do mundo. 'Ser-com-outro' na UBS é uma possibilidade aberta e ligada a escolhas de cada 'ser-aí'.

Porém, o estudo desvelou a necessidade de fortalecimento da comunicação entre docentes e estudantes para que as intencionalidades e as potencialidades da integração ensino-serviço de saúde estejam mais claras para os estudantes antes, durante e após de serem lançados no espaço existencial da UBS.

Esta pesquisa retrata parte de um todo, em determinado momento, a partir de escolhas metodológicas, as quais são características e limitações deste estudo. Contudo, esperamos que possibilite reflexões sobre o fenômeno em questão e que possa, de alguma, forma contribuir para avanços na tão necessária integração ensinoserviço para a formação do estudante, do profissional e do docente, fundamentais para o alcance de melhorias no cuidado da população, o qual deveria ser entendido como objetivo fim daqueles que, em sua cotidianidade, ocupam o mundo do ensino e o do serviço de saúde e, quando juntos, coabitam o espaço existencial da UBS.

\section{ABSTRACT \\ Meanings of training in Basic Health Units for undergraduate students}

This qualitative study had a hermeneutic phenomenological method, supported by Martin Heidegger's concepts that aimed to understand the meaning of internships in the Basic Health Unit (BHU), understood as a possibility to live and 'being-with-the-other' in the working world, 
for ten students in the last period of college. For the students, experiencing the BHU world is perceived as fulfilling a mandatory educational orientation, which can qualify the training and also provides a possibility for the involved people to teach and learn. However, the study revealed the need to strengthen the communication between professors and students, so that the goals and potentials of the teachinghealth service integration are clearer for the students. The students seem to have been introduced in the BHU without much knowledge and appropriation the reasons for their experience in this space.

Descriptors: Internships. Qualitative Research. Higher Education. Primary Health Care. Teaching Care Integration Services.

\section{REFERÊNCIAS}

1. ONU, 1978. Conferência Internacional sobre Cuidados Primários de Saúde. Alma-Ata, URSS, 6-12 de setembro de 1978.

2. UNESCO. Conferência Mundial sobre Educação Superior. Declaração Mundial sobre Educação Superior no Século XXI: Visão e Ação. Paris: UNESCO, 1998.

3. UNESCO. Conferência Mundial sobre Ensino Superior 2009: As Novas Dinâmicas do Ensino Superior e Pesquisas para a Mudança e o Desenvolvimento Social. Paris: UNESCO, 2009.

4. Brasil. Constituição (1988). Constituição da República Federativa do Brasil. Brasília, 1988.

5. Souza AL, Carcereri DL. Estudo qualitativo da integração ensino-serviço em um curso de graduação em Odontologia. Interface Comunic Saúde Educ. 2011;15(39):1071-84.

6. Fonseca GS, Junqueira SR, Zilbovicius C, Araujo ME. Educação pelo trabalho: reorientando a formação de profissionais da saúde. Interface Comunic Saúde Educ. 2014;18(50):571-83.

7. Carvalho SOB, Duarte LR, Guerrero JMA.
Parceria ensino e serviço em unidade básica de saúde como cenário de ensinoaprendizagem. Trab Educ Saúde. 2015;13(1):123-44.

8. Codato LAB, Garanhani ML, González AD, Fernandes MFP. Estudantes, docentes e profissionais na Atenção Básica: coexistência segundo a fenomenologia heideggueriana. Trab Educ Saúde. 201;15(2):519-36.

9. Vasconcelos ACF, Stedefeldt E, Frutuoso MFP. Uma experiência de integração ensinoserviço e a mudança das práticas profissionais: com a palavra os profissionais de saúde. Interface Comunic Saúde Educ. 2016;20(56):147-58.

10. Siqueira-Batista R, Gomes AP, Albuquerque VS, Cavalcanti FOL, Cotta RMM. Educação e competências para o SUS: é possível pensar alternativas à(s) lógica(s) do capitalismo tardio? Ciênc Saúde Coletiva. 2013;18(1):159-70.

11. Ellery AEL, Bosi MLM, Loiola FA. Integração ensino, pesquisa e serviços em Saúde: antecedentes, estratégias e iniciativas. Saúde Soc. 2013;22(1):187-98.

12. Heidegger M. Ser e tempo. Petrópolis: Vozes; Bragança Paulista: Editora Universitária São Francisco, 2006, 598p.

13. Codato LAB. Integração ensino-serviço de saúde: uma compreensão por meio da fenomenologia heideggeriana. Tese (Doutorado em Saúde Coletiva) - Universidade Estadual de Londrina, Londrina, 2015.

14. Garanhani ML, Valle ERM. Educação em Enfermagem. Análise existencial em um currículo integrado sob o olhar de Heidegger. Londrina, EDUEL, 2010.

15. González AD, Bortolotto MSS, Almeida M, Melchior R, Nunes EFPA. Fenomenologia heideggeriana como referencial para estudos sobre formação em saúde. Interface Comunic Saúde Educ. 2016;16(42):809-17. 
16. Minayo MCS(org.). Pesquisa social: teoria, método e criatividade. 15 ed. Petrópolis: Vozes, 2000.

17. Araújo JL, Paz EPA, Moreira TMM. Hermenêutica e saúde: reflexões sobre o pensamento de Hans-Georg Gadamer. Rev Esc Enferm USP. 2012;46(1):200-7.

18. Anéas TV, Ayres JRCM. Significados e sentidos das práticas de saúde: a ontologia fundamental e a reconstrução do cuidado em saúde. Interface Comunic Saúde Educ. 2011;15(38):651-62.

19. Merighi MAB. Enfermeiras obstétricas egressas da Escola de Enfermagem da Universidade de São Paulo: caracterização e trajetória profissional. Tese (Livre Docência) - Escola de Enfermagem, Universidade de São Paulo, São Paulo, 2000.

20. Josgrilberg, RS. O método fenomenológico e as ciências sociais. In: Castro, DSP. (org). Fenomenologia do existir. São Paulo: Universidade Metodista de São Paulo; 2000. p.75- 93.
21. Brasil. Ministério da Saúde. Conselho Nacional de Saúde. Resolução no 466/12 de 12 de dezembro de 2012. Aprova as diretrizes e normas regulamentadoras de pesquisas envolvendo seres humanos. Brasília Diário Oficial da União, 2013.

22. Finkler M, Caetano JC, Ramos FRS. Ética e valores na formação profissional em saúde: um estudo de caso. Ciênc Saúde Coletiva. 2013;18(10):3033-42.

23. Neta AA, Alves MSC. A comunidade como local de protagonismo na integração ensinoserviço e atuação multiprofissional. Trab Educ Saúde. 2016;14(1):221-35.

\section{Correspondência para:}

Lucimar Aparecida Britto Codato

e-mail: lucimarcodato@uel.br

Rua Fernando de Noronha, 608

86020-300 Londrina/PR 